\title{
Verzeichnis der Abbildungen.
}

\section{Text-Illustrationen.}

Seite

Fig. 1. Augustusbüste im capitolinischen Museum (nach Photogr.) . . 24

Fig. 2. Statue des Augustus von Primaporta im Vatican (nach Photogr.) 25

Fig. 3. Colossalkopf des Augustus im MLus. Chiaramonti (nach Photogr.) 28

Fig. 4. Colossalkopf im Giardino della Pigna (nach Photogr.) . . . . 29

Fig. 5. Angeblich alter Augustus im Vatican (nach Photogr.) . . . . 30)

Fig. 6. Augustus als junger Mann in Florenz (nach Photogr.) . . . . . 35

Fig. 7. Bronzebuistchen des Augustus im Louvre, Face und Profil (nach Fröhner Musée de France) . . . . . . . . . . . . . . 38

Fig. 8. Jugendlicher Augustus (?) in Madrid (nach Phot. des Gypsabg.) 40

Fig. 9. Augustuskopf in München (nach Photogr.) . . . . . . . . 42

Fig. 10. Bronzebüstchen der Livia in Louvre, Face und Protil (nach Fröhner Musée de France) . . . . . . . . . . . . . 89

Fig. 11. Kopf einer sitzenden Statue (Livia?) in Mnseo arqueol. zn Madrid (nach Skizze) . : . . . . . . . . . . . . . . . . . . 92

Fig. 12. Kopf der borghesischen Livia-(?) Statue im Lourre, Face und Profil (nach Mongez) . . . . . . . . . . . . . . . 102

Fig. 13. Frauenkopf in Toulouse (nach Skizze) . . . . . . . . . . 113

Fig. 14. Frauenbüste in Berlin (nach denı Original) . . . . . . . . . 114

Fig. 15. Frauenbüste in Berlin (nach dem Original) . . . . . . . . . 114

Fig. 16. Basaltkopf der Octavia (?) im Louvre (nach Photogr.) . . . . 11!

Fig. 17. Kopf der sog. Marcellusstatue in Vatican, Face und Profil (nach Mongez) . . . . . . . . . . . . . . . . . . . . 123

Fig. 18. Knabenkopf in Arles (nach Photogr.) . . . . . . . . . . . 124

Fig. 19. Tiberiusstatue von Veji im Museo Chiaramonti (nach Photogr.) 145

Fig. 20. Tiberiusstatue von Piperno im Mus. Chiaramonti (nach Photogr.) 146

Fig. 21. Kopf derselben (nach dem Original) . . . . . . . . . . . . . . . . . . 147

Fig. 22. Jugendlicher 'Tiberius in Berlin (die Torderansicht nach Photographie, die Protilansicht nach dem Original) . . . . . . 154

Fig. 23. Kopf eines jungen Claudiers im Vatican (nach dem Original) . 169

Fig. 24. Claudiers ștatue von Veji (Germanicus?) im Lateran (nach Photogr.) 170

Fig. 25. Claudischer .Jünglingskopf im Lateran, Face und Profil (nach dem Original) . . . . . . . . . . . . . . . . 171 
Fig. 26. Jünglingskopf in der Akademie von S. Fernando in Madrid (nach Photographie des Gypsabgusses) . . . . . . . . . . . 175

Fig. 27. Oberteil der sog. Domitia im Museo Chiaramonti (nach Photogr.) 182

Fig. 28. Kopf im Pal. (ligi zu Rom (ang. jüngere Agrippina), Face und Profil (nach Photographie) . . . . . . . . . . . . . 185

Fig. 29. Büste der sog. Messalina in Florenz (nach Photographie) . . . 188

Fig. 30. Büste der älteren Agrippina im Louvre (nach Photographie) , 190

Fig. 31. Statue der Agrippina in München (nach Photographie) . . . 192

Fig. 32. Sog. Messalina kopf in München, Face und Profil (nach Photogr.) 193

Fig. 33. Büste der sog. jüngeren Agrippina in Köln (nach dem Original) 194

Fig. 34. a. und b. Kopf der Statue des jiingeren Drusus in Turin, Face und Profil (nach Mongez) . . . . . . . . . . . . . . . 200

Fig. 35̃. Kopf des jüngeren Drusus in Museo arqueolog. zu Madrid (nach Skizze) . . . . . . . . . . . . . . . . . . . . 201

Fig. 36. Kopf des jüngeren Drusus in Cordova (nach Photographie) . . 201

Fig. 37. Büste des jüngeren Drusus in Erbach, Face u. Profil (nach Photogr.) 202

Fig. 38. Campana'sche Büste des jüngeren Drusus im Louvre (die Vorderansicht nach Photographie, die Profilansicht nach Skizze) . . 203

Fig. 39. Bronzekopf des Nero Drusus (?) im Louvre, Face und Profil (nach Mongez) . . . . . . . . . . . . . . . . . 212

Fig. 40. Büste des sog. Nero Drusus in Erbach (nach Photographie). . 213

Fig. 41. Sog. Antoniakopf im Museo Chiaramonti (nach dem Original) . 219

Fig. 42. Matronenkopf im Museo Chiaramonti (nach dem Original) . . . 220

Fig. 43. a. und b. Sog. Cly tia im brit. Museum, Face und Profil (nach Hübner Bildnis einer Römerin). . . . . . . . . . . . . . . . 222

Fig. 44. Oberteil der fälschlich sog. Agrippina im Capitol (nach Photogr.) 246

Fig. 45. Ca meo Hawkins (nach Wieseler Gött. Nachrichten) . . . . . 277

Fig. 46. Kopf des Caligula (?) im Lateran (nach dem Original) . . . . 305

Fig. 47. Bronzebüste des Caligula in Turin, Face und Profil (nach Mongez) 307

Fig. 48. Büste des Claudius (?) im Capitol (nach Photographie) . . . . 331

Fig. 49. Colossalkopf des Claudiu s von Otricoli im Vatican (nach Photogr.) 333

Fig. 50. Bronzebüste des Claudius im Louvre, Face u. Profil (nach Mongez) 336

Fig. 51. a. und b. Claudius büste in Madrid, Face und Profil (nach Mongez mit umgekehrten Seiten) . . . . . . . . . . . . . . . . 338

Fig. 52. Came o in Windsor Castle (nach dem Lichtdruck in der Archaeologia) 342

Fig. 53. Statue der sog. Messalina und des Britannicus im Louvre (nach Mongez) . . . . . . . . . . . . . . . . . . . . 361

Fig. 54. Knabenkopf des Nero im Capitol (nach Skizze). . . . . . . 391

Fig. 55. Bärtiger Nerokopf im Capitol (nach Photographie) . . . . . 392

Fig. 56. Angeblicher Nerokopf im Vatican (nach dem Original) ... . . 333

Fig. 57. Nerokopf im Museum des Palatin (nach Skizze) ' . . . . . . 394

Fig. 58. Bärtige Nerobüste im Louvre (nach Photographie) . . . . . 397

Fig. 59. Nerokopf im brit. Museum (nach Photographie) . . . . . . 398 


\section{Tafeln.}

I. Statue des Augustus von Primaporta in Braccio nuovo des Vaticans.

III. Jugendlicher Augustus im Museo Chiaramonti.

III. A ugustus (sog. Caligula) in der Statuengallerie des Vaticans.

IV. Bronzekopf des Augustus in der vaticanischen Bibliothek.

V. Angebliche Statue der Livia von Pompeji in Neapel.

VI. Relief in San Vitale zu Ravenna.

VII. Büste des Tiberius in Louvre.

VIII. Statue des sog. Drusus von Pompeji in Neapel.

IX. Statue von Veji im Lateran: Germanicus oder der j. Drusus.

X. Statue des Germauicus von Gabii im Louvre.

XI. Büste des Germanicus im Schloss Erbach.

XII. Büste eines jungen Clauddiers im capitolinischen Museum.

XIII. Statue eines Claudiers (Ner o Drusus?) von Cervetri im Lateran.

XIV. Statue der Antonia (?) im Louvre (Samml. Campana).

XV. Büste der ătteren Agrippina in capitolinischen Museum.

XVI. Statue des sog. Caligula von Gabii in Louvre.

XVII. Statue des Claudius in der Rotonde des Vaticans.

XVIII. Kopf des Claudius im Museum zu Braunschweig.

XIX. Statue der jüngeren Agrippina von Cervetri im Mus. des Lateraus.

XX. Statue der jüng. Agripp in a (?) in der Glyptothek zu München.

XXI. Jüngere Agrip pina (?) im Museo Chiaramonti.

XXII. Sitzende Matronenstatue im Museum zu Neapel.

XXIII. Ne rokopf in München.

XXIV. Bronzekopf des Nero in der vaticanischen Bibliothek.

XXV. Büste des Nero im Louvre.

XXVI. Erste Gemmentafel '.

XXVII. Zweite Gemmentafel.

XXVIII. Dritte Gemmentafel.

XXIX. Gemma Augustea in Wien.

XXX. Der grosse Pariser Came o.

XXXI. Der Cameo mit den Fruchthornbüsten in Wien.

XXXII. Erste Münztafel 1.

XXXIII. Zweite $\mathbf{M}$ ünztafel.

XXXIV. Dritte Münztafel.-

XXXV. Vierte Münztafel.

1 Die năheren Verweisungen für die Gemmen- und Mñnztafeln s. an Schluss. 